Research Article

\title{
Research of the Rheological Modification Mechanism of Crumb Rubber-Modified Asphalt Containing Polyamide 6 Additive
}

\author{
Zhihua $\operatorname{Tan}^{1}$ and Jijing Wang $\mathbb{D}^{2}$ \\ ${ }^{1}$ Changsha University of Science \& Technology, Changsha 410004, China \\ ${ }^{2}$ School of Traffic \& Transportation Engineering, Changsha University of Science \& Technology, Changsha 410004, China \\ Correspondence should be addressed to Jijing Wang; wangjijing@csust.edu.cn
}

Received 9 April 2020; Revised 10 May 2020; Accepted 29 May 2020; Published 13 June 2020

Academic Editor: Fan Gu

Copyright ( 2020 Zhihua Tan and Jijing Wang. This is an open access article distributed under the Creative Commons Attribution License, which permits unrestricted use, distribution, and reproduction in any medium, provided the original work is properly cited.

\begin{abstract}
In the past few decades, the rapid growth of automobile production in China has led to the scrapping of a large number of tires. How to dispose of tires has become a significant challenge. The addition of crushed rubber to asphalt binder not only can improve the performance of asphalt mixtures but also is an effective and environmentally friendly way to recycle scrapped tires. However, rubber asphalt mixtures demand higher production temperatures than conventional asphalt binders due to the higher viscosity of asphalt rubber binder. The main objective of this study is to evaluate the rheological properties of rubber-modified asphalt by adding polyamide 6 and investigate the modification mechanism of crumb rubber-modified asphalt (CRMA) after adding polyamide 6 . To this end, the content of waste rubber in the prepared rubber asphalt was $20 \%$. The conventional laboratory rheological tests were employed to evaluate the performance of crumb rubber-modified asphalt after adding polyamide 6 . Furthermore, to investigate the interaction mechanism of crumb rubber and asphalt, a series of advanced tools, including the scanning electron microscopy (SEM) test, differential scanning calorimeter (DSC) test, and Fourier transform infrared spectroscopy (FTIR) test, were conducted. From the experimental results obtained, it may be concluded that crumb rubber-modified asphalt with adding polyamide 6 not only improves the engineering properties of the rubber-modified asphalt but also improves the performance of rubber asphalt. From the FTIR and SEM tests, it is concluded that there is no new functional group in the mixing process of crumb rubber and the asphalt, which contributes to the storage stability of asphalt binder and runway.
\end{abstract}

\section{Introduction}

At present, China's tire production ranks first in the world, but the utilization rate of used tires is meager, less than $50 \%$. The annual waste tires have reached more than 10 million tons and are still increasing year by year $[1,2]$. Because waste tires are thermosetting polymer materials, they are resistant to high temperature, corrosion, and wear and are difficult to degrade under natural conditions. More than $30 \%$ of used tires in China are burned, buried, and piled up as garbage $[3,4]$. This will not only occupy a large number of land resources, pollute the atmosphere, soil, and water resources, and bring serious environmental and ecological problems but also cause fire easily, produce toxic and harmful smoke and gas, and pose a great threat to human health [5].
Therefore, in the face of the current situation of scarce natural resources, it is of great practical significance to study how to effectively use used tires, realize the recycling of resources, and reduce the pollution of used tires to the environment.

The plastic track has excellent performance and convenient use. It has been well received and has been officially designated by the International Olympic Committee as one of the prerequisites for the international competition venue. Most of the polyurethane plastic track currently laid is mixed type, and its basic formula contains heavy metal catalysts $[6,7]$, which causes the plastic track in the pavements to be poisonous and the cost of laying is too high $[8,9]$, International Sports Track Technology Association (IST). As early as 1994, it was proposed to "not accept the use of the sports 
system with TDI-containing polyurethane system." The hybrid plastic track has been eliminated, and various new plastic runways have emerged, which are bonded with polyurethane adhesive. The preparation of plastic track for waste rubber powder has become a research hotspot $[10,11]$. Achary PS [12] used TDI adhesive bonding waste rubber powder to make paving materials. Wang Wei et al. [13] used TDI and modified diphenylmethane diisocyanate (MDI) which is used as an adhesive to bond SBR waste rubber particles to a porous polyurethane surfacing layer in a ratio of $1: 3.5$ (mass ratio). Zhu Xinming [13] used a large-tonnage flat vulcanizing machine to mold waste tire rubber to form a combined plastic layer. These studies have achieved excellent results, but crumb rubber is only used on the runway surface. Crumb rubber can also be added to the asphalt layer of the rubber runway.

Recently, reclaimed rubber obtained from tires has been used in a valuable way in paving as an elastic binder additive. Research has shown that the addition of crumb rubber to virgin asphalt can produce asphalt pavements that exhibit decreased traffic noise, reduced maintenance costs, higher resistance to rutting, fatigue cracking, and thermal cracking as well as a reduction in the thickness of asphalt overlays and reflective cracking potential [14-21]. However, asphalt rubber mixtures demand complex modification and construction technology, which restricts its wide use. Over the years, numerous additives have been studied to enhance the compatibility and reaction of crumb rubber to asphalt so as to improve the performance of rubber asphalt. Liu et al. $[22,23]$ added TOR (transpolyoctenamer rubber active agent) as an additive to rubber-modified asphalt. The results show that TOR reacts with sulfur on the surface of rubber and asphalt to form a network structure between rubber and asphalt. Fini et al. [24] added bioadhesive to rubber-modified asphalt, which promoted cross linking between rubber and asphalt and improved segregation of rubber-modified asphalt. The combination of rubber and polyethylene, such as high-density polyethylene [25], low-density polyethylene [26], or recycled polyethylene [27], can improve the hightemperature performance and water stability of rubbermodified asphalt. The combination of rubber and polyethylene [28] can improve the low-temperature performance of rubbermodified asphalt. The rubber and EVA [29], polyphosphoric acid composite, can effectively improve the storage stability and antiaging properties of rubber-modified asphalt. In this paper, polyamide 6 with excellent compatibility with asphalt is added to the rubber-modified asphalt. Although previous studies have demonstrated that the addition of polyamide 6 has turned out to be a viable choice in asphalt pavements, the rheological modification mechanism and its improvement in modification technology of polyamide 6 additive on crumb rubber-modified asphalt have not been clearly understood yet.

In the study, several conventional and microscopic tests were carried out. The conventional tests include penetration test, elastic recovery test, softening point test, Brookfield viscosity tests, and DSR test. Further, the microscopic tests include scanning electron microscopy (SEM) test, differential scanning calorimeter (DSC) test, and Fourier transform infrared spectroscopy (FTIR) test. The emphasis of this study has been placed on analyzing the effects of polyamide 6 on the rheological properties of CRMA at different temperatures, as well as the rheological modification mechanism of polyamide 6 on CRMA. It is exposed that the research results of this study will benefit the engineering practice of using polyamide 6 technology in CRMA and improve the content of rubber in modified asphalt.

\section{Materials Preparation}

All raw material models, manufacturers, and methods of used in this paper are listed in Table 1.

In this paper, 60 mesh rubber powders were selected as the asphalt modifier, which was produced by crushing truck tires. Technical performance parameters are listed in Table 2.

The preparation method of rubber powder-modified asphalt is divided into the wet method and dry method, and the wet method is more commonly used. The wet method is to add rubber as a modifier to the neat asphalt binder. The dry process uses rubber instead of a portion of the fine aggregate and is added directly to the asphalt mixture. The rubber-modified asphalt produced by the wet method has high viscosity and elasticity. The dry method is simple to operate, but the rubber only plays a role in filling in the mixture, resulting in poor water stability of the road surface.

In this paper, a rubber-modified asphalt with polyamide 6 as an additive is prepared by a wet method. The specific preparation steps are as follows:

(1) The polyamide is placed in formic acid to be sufficiently dissolved, wherein the ratio of the mass of the polyamide to the formic acid is $1: 10$. Then, the impurity-removed rubber is placed in a polyamide formic acid solution, wherein the mass ratio of the polyamide to the rubber powder is $1: 10$; then, the formic acid is dried in an oven at $105^{\circ} \mathrm{C}$ and cooled to room temperature to obtain an activated rubber.

(2) The neat asphalt binder is heated in an oven to a temperature of 180 to $200^{\circ} \mathrm{C}$.

(3) The treated rubber is then dried in an oven at $60^{\circ} \mathrm{C}$ and added to the neat asphalt binder.

(4) The high-speed shearing device is used to uniformly disperse the rubber powder in the asphalt, wherein the shear rate is $2000 \mathrm{r} / \mathrm{min}$, the temperature is $160-200^{\circ} \mathrm{C}$, and the time is $30-90 \mathrm{~min}$.

(5) Finally, the activated rubber-modified asphalt was placed in an oven at $135^{\circ} \mathrm{C}$ for $1 \mathrm{~h}$.

\section{Test and Analysis}

3.1. Penetration Test. Table 3 can conclude that when crumb rubber content was $10 \%, 15 \%, 20 \%$, and $30 \%$, compared with the neat asphalt binder, the penetration of crumb rubbermodified asphalt $\left(15^{\circ} \mathrm{C}\right)$ was reduced by $8.7 \%, 22.7 \%, 27.4 \%$, and $33.8 . \%$. As the temperature increased, the penetration increased. However, as the crumb rubber dosage increases, 
TABLE 1: Technical indicators of neat asphalt binder.

\begin{tabular}{|c|c|c|c|c|}
\hline Index & Unit & Test result & Technical requirement & Test method \\
\hline Penetration $\left(25^{\circ} \mathrm{C}, 100 \mathrm{~g}, 5 \mathrm{~s}\right)$ & $0.1 \mathrm{~mm}$ & 69.3 & $60 \sim 80$ & \multirow{2}{*}{ JTG E20 T0604 } \\
\hline Penetration index (PI) & - & -0.825 & $-1.5 \sim+1.0$ & \\
\hline Softening point ( $\mathrm{R}$ and $\mathrm{B}$ ) & ${ }^{\circ} \mathrm{C}$ & 47.2 & $\geq 46$ & JTG E20 T0606 \\
\hline $5^{\circ} \mathrm{C}$ ductility & $\mathrm{cm}$ & $>100$ & $>100$ & JTG E20 T0605 \\
\hline \multicolumn{5}{|l|}{ After TFOT } \\
\hline Quality change & $\%$ & 0.20 & $\leq \pm 0.8$ & JTG E20 T0609 \\
\hline Residual penetration ratio $\left(25^{\circ} \mathrm{C}\right)$ & $\%$ & 65 & $\geq 61$ & JTG E20 T0604 \\
\hline Residual ductility $\left(15^{\circ} \mathrm{C}\right)$ & $\mathrm{cm}$ & 7.8 & $\geq 6$ & JTG E20 T0605 \\
\hline
\end{tabular}

TABLE 2: Technical parameters of rubber powder.

\begin{tabular}{lccc}
\hline Parameter & Unit & Result & Experiment method \\
\hline Moisture & $\%$ & 1.3 & HG/TXXX-2001 7.2.2 \\
Ash & $\%$ & 9.1 & GB4498 \\
Acetone extract content & $\%$ & 12.9 & $\mathrm{~GB} / \mathrm{T} 3516$ \\
Strength & $\mathrm{g} / \mathrm{cm}^{3}$ & 1.28 & $\mathrm{~GB} / \mathrm{T} 533$ \\
Tensile strength & $\mathrm{MPa}$ & 17 & $\mathrm{~GB} / \mathrm{T} 528$ \\
Elongation at break & $\%$ & 648 & $\mathrm{~GB} / \mathrm{T} 52$ \\
\hline
\end{tabular}

TABLE 3: Test results of crumb rubber-modified asphalt.

\begin{tabular}{|c|c|c|c|c|c|c|c|}
\hline \multirow{2}{*}{\multicolumn{2}{|c|}{ Property }} & \multirow{2}{*}{ Unit $(\mathrm{mm})$} & \multicolumn{5}{|c|}{ Crumb rubber $(\%)$} \\
\hline & & & 0 & 10 & 15 & 20 & 30 \\
\hline \multirow{3}{*}{ Penetration } & $15^{\circ} \mathrm{C}$ & & 26.1 & 20.4 & 16.7 & 14.6 & 13.7 \\
\hline & $25^{\circ} \mathrm{C}$ & 0.1 & 69.3 & 63.3 & 53.6 & 50.3 & 45.9 \\
\hline & $30^{\circ} \mathrm{C}$ & & 115.4 & 88.5 & 79.8 & 66.5 & 56.5 \\
\hline \multicolumn{2}{|c|}{ PI } & & -0.825 & -0.425 & -0.348 & -0.189 & 0.029 \\
\hline
\end{tabular}

the amplitude increases. The addition of crumb rubber can reduce the rheological properties of asphalt. It indicates that the low-temperature crack resistance of crumb rubbermodified asphalt decreases; that is, the hardness of crumb rubber-modified asphalt increases at a low temperature, and brittle fracture is likely to occur when the crumb rubbermodified asphalt is stressed at low temperature [30]. As the content of crumb rubber increased from $10 \%$ to $30 \%$, the penetration index of crumb rubber-modified asphalt increased from -0.425 to 0.029 , indicating that the thermal sensitivity of crumb rubber-modified asphalt was improved.

3.2. Force Ductility Test. As Table 4 shows, the ductility of rubber-modified asphalt showed a trend of decreasing first and then increasing. As the number of rubbers increases in a certain range, the rubber particles per unit volume increase, which tends to cause stress concentration, and the ductility will decrease within this range. As the rubber powder content continues to increase, the swelling of the rubber powder in the asphalt continues to increase, the light components in the neat asphalt binder are continuously absorbed, the proportion of the asphaltenes increases, the neat asphalt binder becomes hard, and the deformation ability decreases. Moreover, the asphaltene and the rubber form a network structure, which further enhances the flexibility of the rubber-modified asphalt, and the ductility is improved. The ratio of the ductility to the tension is taken as the compliance in extension, and the value is used to measure the low-temperature viscosity and toughness of asphalt, which can better reflect the low-temperature performance of asphalt [31]. Compliance in the trend of extension also further illustrates this phenomenon.

The maximum tensile force can indicate the resistance of the asphalt to external forces at low temperatures. Unlike the ductility, the maximum tensile force occurs in the middle section of the tensile process of the specimen and is less affected by the stress concentration, its physical meaning is clear, and it has a higher correlation with the maximum tensile stress of the asphalt pavement at low temperatures [32]. Therefore, the maximum tensile force can be used to characterize the lowtemperature performance of rubber-modified asphalt. As shown in Table 4, as the amount of activated rubber increased, the maximum tensile force $F_{\mathrm{Max}}$ of the rubber-modified asphalt increased. That is, the low-temperature crack resistance of the rubber-modified asphalt is improved.

3.3. Brookfield Viscosity Test. The viscosity at $175^{\circ} \mathrm{C}$ has a guiding effect on the actual construction. The higher the viscosity of the modified asphalt at $175^{\circ} \mathrm{C}$, the higher the resistance of the asphalt to high temperature and the better the softening resistance. When the viscosity is too high, the high-temperature performance of the asphalt is excellent, but it is not easy to compact during construction, and the road surface is prone to water damage.

As shown in Figure 1, the greater the rubber content, the higher the viscosity of the modified asphalt, because as the 
TABLE 4: Force ductility test result of crumb rubber-modified asphalt at $5^{\circ} \mathrm{C}$.

\begin{tabular}{lccc}
\hline Crumb rubber content $(\%)$ & Ductility $(\mathrm{cm})$ & $F_{\text {Max }}(\mathrm{N})$ & Compliance in extension \\
\hline 0 & 64.34 & 72.48 & 0.888 \\
10 & 51.9 & 80.1 & 0.648 \\
15 & 48.6 & 89.5 & 0.543 \\
20 & 52.2 & 91.6 & 0.570 \\
30 & 55.1 & 93.4 & 0.596 \\
\hline
\end{tabular}

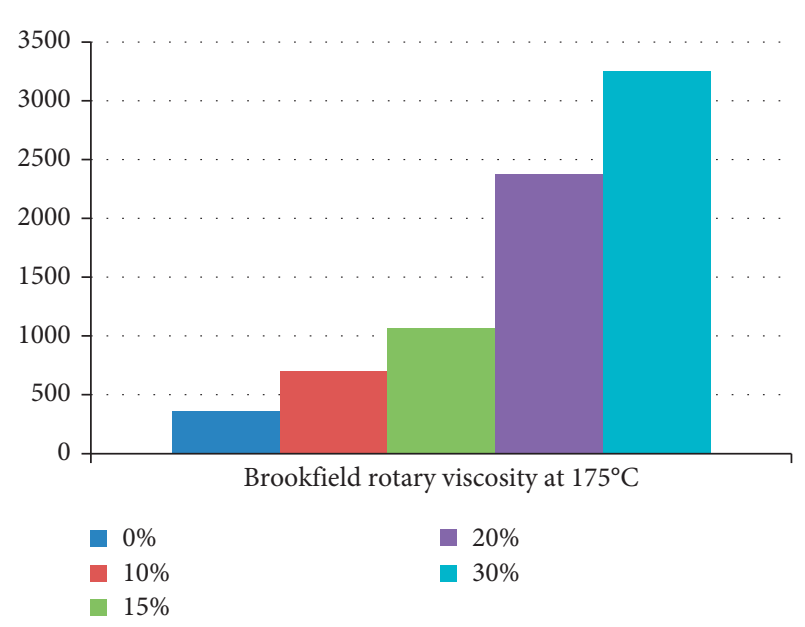

FIGURE 1: Brookfield rotary viscosity of crumb rubber-modified asphalt (MPa.s).

amount of activated rubber increases, a large amount of light components in the asphalt is swollen and absorbed by the rubber. The asphaltene and gum content is increased, and the asphalt has a high viscosity.

The Technical Guide for Design and Construction of Rubber Asphalt and Mixtures stipulates that the hightemperature viscosity of rubber powder-modified asphalt should be between 1000 and $3000 \mathrm{MPa}$ s. When the rubber content is $30 \%$, the specification is not satisfied.

3.4. Dynamic Shear Rheological Test. The rutting factor $\left(G^{*} /\right.$ $\sin \delta$ ) is the ratio of the complex modulus $G^{*}$ to the sine of the phase angle $\delta$. The complex modulus characterizes the ability of the viscoelastic material to resist deformation, that is, the magnitude of elasticity. The phase angle characterizes the stickiness. As Figures 2 and 3 show, the ratio of the two represents the antirutting ability of asphalt. The greater the rutting factor, the greater the flexibility of the asphalt and the stronger the rutting resistance [33]. The greater the rubber powder content, the greater the rutting factor of the modified asphalt. This is because as the rubber content increases, the elastic particles in the liquid phase of the asphalt increase, the elasticity of the modified asphalt increases as the amount increases, and the probability that the swollen rubber particles cross each other to form a spatial network structure increases. The ability to resist external stresses increases.

3.5. Fluorescence Microscopy. In order to further observe the fusion degree of activated rubber and asphalt, a fluorescence

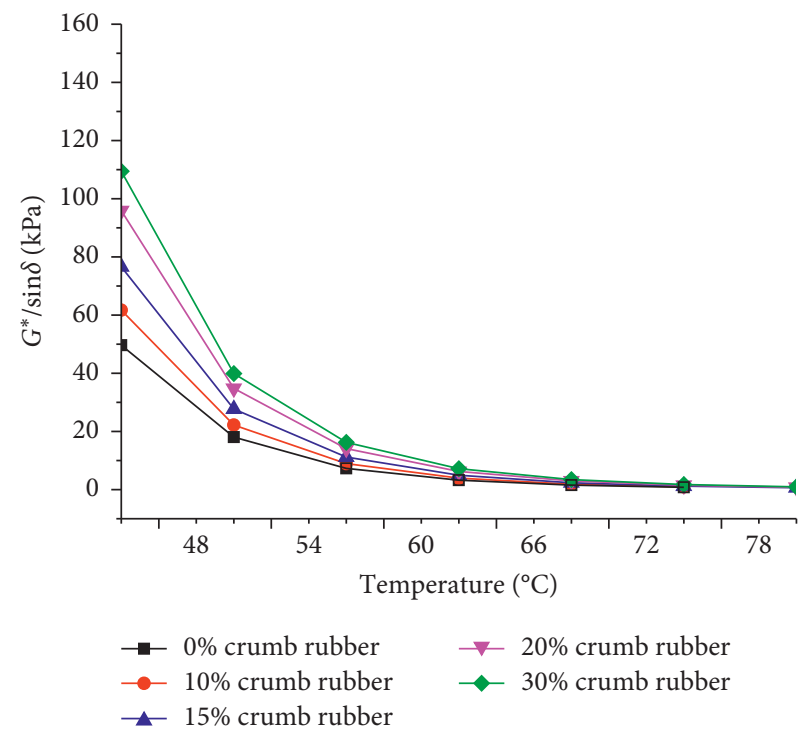

Figure 2: Rutting factor $G^{*} / \sin \delta$ with different temperatures.

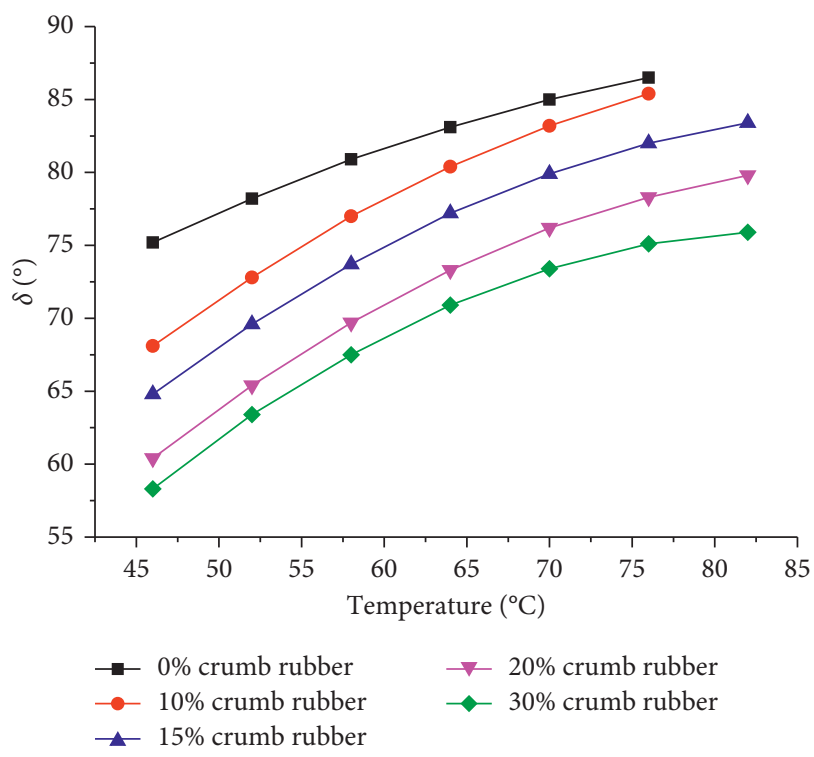

Figure 3: Phase angle $\delta$ with different temperatures.

microscope experiment was carried out. The fluorescent substance in the sample was stimulated by a certain wavelength of light to emit fluorescence, and then the morphology and distribution of the substance were observed under the microscope [34]. In this paper, the blue light filter group is used as the excitation light, and the rubber powder 
will reflect the longer wavelength yellow light under the excitation of blue light, while the asphalt does not excite any light and is black. Therefore, the phase morphology of the rubber powder-modified asphalt can be tested by clearly distinguishing the rubber powder (yellow-green) and the asphalt (black) by a fluorescence microscope. In this paper, the fluorescence microscopy test was carried out on ordinary rubber powder-modified asphalt and rubber powder with additives-modified asphalt. The results are shown in Figure 4.

As shown in Figure 4, the ordinary rubber powdermodified asphalt has obvious yellow bright spots in the fluorescence microscope photo, and the ordinary rubber powder is unevenly distributed in the neat asphalt binder, and there are large particles. The rubber powder with additives-modified asphalt fluorescence microscope has no obvious bright spots, the modified asphalt is in a uniform state, the rubber powder with additives particles is small, and the dispersion in the neat asphalt binder is better. The rubber powder and the asphalt form a stable system. Therefore, it has been proved by fluorescence microscopy that polyamide 6 acts as a compatibilizer between the rubber powder and the asphalt, increasing the compatibility of the rubber powder with the neat asphalt binder.

3.6. Scanning Electron Microscopy. The scanning electron microscopy of the rubber powder before and after activation was carried out, and the magnification was 1500 times, as shown in Figure 5.

The following can be seen from Figure 5:

(1) The surface of the unactivated rubber powder is relatively smooth, and the surface of the rubber powder activated by the polymer coating is rough, exhibits a certain floc structure, and has many grooves and convex portions, and the rough surface has a large surface. The specific surface area can improve the swelling effect of the light component of the rubber powder in the asphalt and improve the storage stability of the rubber powder-modified asphalt.

(2) There is no microattachment on the surface of the in rubber powder with additives, but there are many microattachments on the surface and groove of the rubber powder with additives coated with polymer, and the attachment is evenly distributed, which indicates that polyamide 6 is uniformly coated on the surface of the rubber powder.

(3) The surface of the coated activated rubber becomes rough, which will make it better to blend with the asphalt and also better blend it with other analogs. It can not only improve the strength of the rubber track base layer but also promote the fusion of the rubber track base layer and the surface layer and also increase the consumption of waste rubber, which is conducive to environmental protection.

In order to more clearly observe the degree of bonding between activated rubber and asphalt, the paper examined the scanning electron microscopy of ordinary rubber powder-modified asphalt and activated rubber powdermodified asphalt. The results are shown in Figure 6.

As shown in Figure 6, although the ordinary rubber powder-modified asphalt is physically shear-dispersed, the system still contains large unswelled irregular rubber powder particles, and the rubber powder has a clear interface with the asphalt, and the dispersion is uneven. It is easy to aggregate, while the unswelled rubber particles in the activated rubber powder-modified asphalt are small, the interface is fuzzy, and the rubber powder with additives is uniformly dispersed in the asphalt. It can be seen that the polymer coated on the surface of the rubber powder with additives can effectively improve the compatibility of the rubber powder with the asphalt and improve the swelling degree of the rubber powder in the asphalt.

3.7. Infrared Scanning. Through the previous tests, it can be found that the treated waste rubber can be well fused with the asphalt, but the process is a physical reaction or a chemical reaction, which requires further exploration. Therefore, the infrared spectroscopy test was carried out in this paper, which is aimed at 90\# neat asphalt binder, common. The three kinds of asphalts, rubber powdermodified asphalt, and activated rubber powder-modified asphalt, were tested by infrared spectroscopy. The results are shown in Figure 7.

As shown in Figure 7, the infrared spectra of neat asphalt binder show strong absorption peaks mainly in the range of $2800-3000 \mathrm{~cm}^{-1}$ and $1300-1700 \mathrm{~cm}^{-1}$. The absorption peaks at $2849 \mathrm{~cm}^{-1}$ and $2918 \mathrm{~cm}^{-1}$ are the strongest in the range of $2800-3000 \mathrm{~cm}^{-1}$, which are mainly caused by C-H bending vibration of naphthene and alkanes at $2849 \mathrm{~cm}^{-1}$, while the absorption peaks at $2918 \mathrm{~cm}^{-1}$ are caused by $\mathrm{C}-\mathrm{CH}_{2}-$ stretching vibration; in the range of $1300-1700 \mathrm{~cm}^{-1}$, the absorption peaks at $1599 \mathrm{~cm}^{-1}, 1455 \mathrm{~cm}^{-1}$, and $1370 \mathrm{~cm}^{-1}$ are the strongest, and the absorption peaks at $1599 \mathrm{~cm}^{-1}$ are caused by benzene ring skeleton. Conjugated double bond $\mathrm{C}=\mathrm{C}$ bond stretching vibration and $\mathrm{C}=\mathrm{O}$ bond absorption cause, the absorption peak at $1455 \mathrm{~cm}^{-1}$ is caused by C-H bending vibration; the absorption peak at $1370 \mathrm{~cm}^{-1}$ is the result of $\mathrm{C}-\mathrm{H}$ in-plane stretching vibration in $-\mathrm{CH}_{2}-1$; the peak below $1000 \mathrm{~cm}^{-1}$ is the absorption peak of unsaturated $\mathrm{C}-\mathrm{H}$ out-plane vibration, in which the range of $650-910 \mathrm{~cm}^{-1}$ is also called benzene ring substitution zone of asphalt, mainly caused by $\mathrm{C}-\mathrm{H}$ out-plane swaying on benzene ring.

According to the interpretation of infrared spectra of neat asphalt binder, the composition of asphalt is very complex, including saturated aromatic hydrocarbons such as alkanes and naphthenes, as well as aromatic compounds and heteroatom derivatives such as $\mathrm{O}$. Compared with infrared spectra of neat asphalt binder and modified asphalt with ordinary rubber powder, infrared spectra of neat asphalt binder are almost the same as those of modified asphalt with activated rubber powder. It can be seen that the peaks of rubber powder at $2913 \mathrm{~cm}^{-1}, 2845 \mathrm{~cm}^{-1}, 1421 \mathrm{~cm}^{-1}$, and $1370 \mathrm{~cm}^{-1}$ are similar to those of asphalt and are covered by 


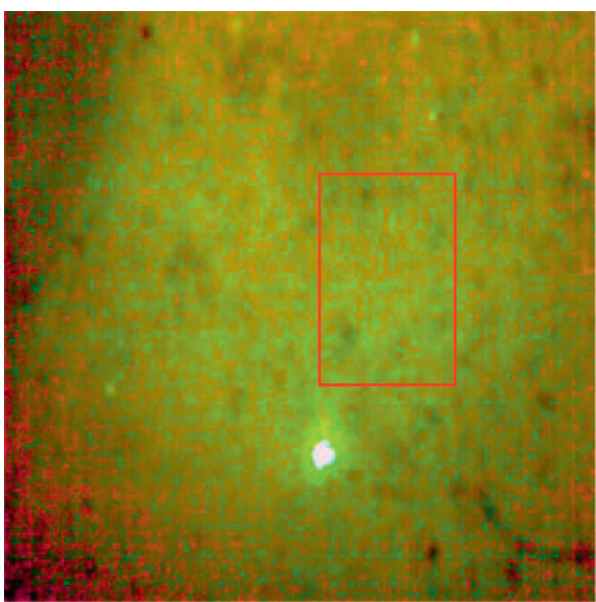

(a)

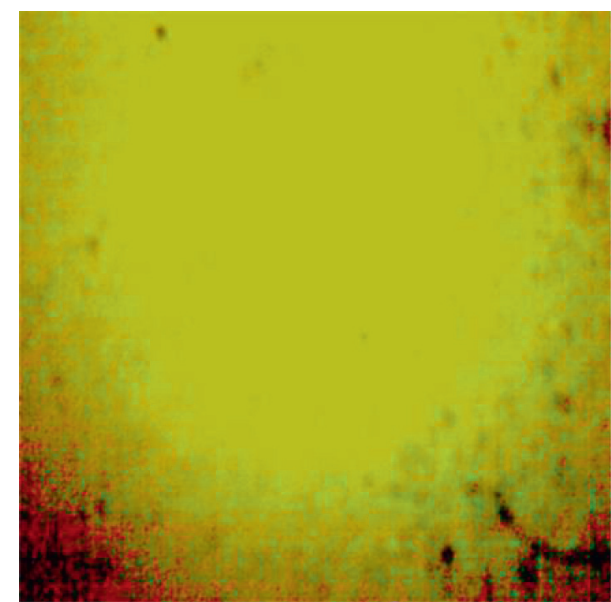

(b)

FIGURE 4: Fluorescence microscopy photo of ordinary rubber powder-modified asphalt and rubber powder with additives-modified asphalt: (a) ordinary rubber powder-modified asphalt; (b) rubber powder with additives-modified asphalt.

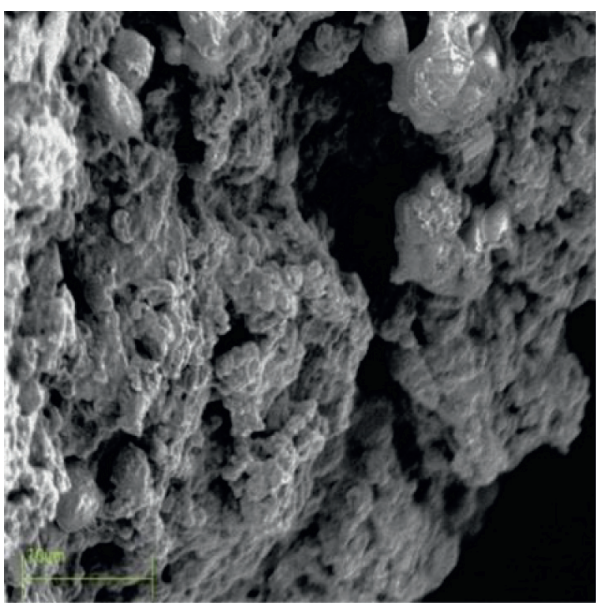

(a)

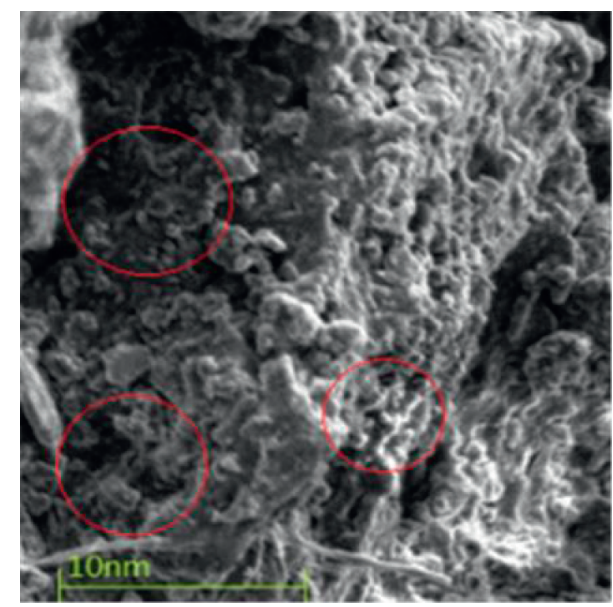

(b)

Figure 5: Electron microscopic scan of ordinary rubber powder and rubber powder with additives: (a) ordinary rubber powder (1500x); (b) rubber powder with additives (1500x).

asphalt peaks, and there are no new peaks, indicating that rubber powder is added to the base. There is hardly any chemical reaction in asphalt, which belongs to physical blending [35].

Compared with neat asphalt binder, three peaks of $3295 \mathrm{~cm}^{-1}, 1633 \mathrm{~cm}^{-1}$, and $1537 \mathrm{~cm}^{-1}$ appeared in activated rubber powder-modified asphalt. Compared with the infrared spectra of activated rubber powder in Chapter 2, it can be seen that the peaks at $3295 \mathrm{~cm}^{-1}$ are $\mathrm{N}-\mathrm{H}$ bond absorption peaks, at $1633 \mathrm{~cm}^{-1}$ are $\mathrm{NH}_{2}$ amide I absorption peaks, and at $1537 \mathrm{~cm}^{-1}$ are $\mathrm{NH}$ amide II absorption peaks, among others. The peaks are the same as those of ordinary rubber powder-modified asphalt. It shows that polyamide has existed in modified asphalt, and there is no new material except asphalt, rubber powder, and polyamide. There is no chemical reaction between activated rubber powder coated with polymer and neat asphalt binder. Because the rubber runway surface contains rubber, based on the principle of similar compatibility, the runway surface with rubber will be better fused to the base, and the activation process does not produce substances that are not conducive to the fusion.

3.8. Differential Scanning Test. For the runway, stability is very important, and the support provided by the runway should be durable enough. Then, it is very important to know the stability of the activated rubber runway and whether there will be corrosion. Based on this, the differential scanning experiment is carried out in this paper.

With the change of temperature, asphalt shows three states: glass state, viscoelastic state, and viscous flow state [36]. When the temperature is lower, the asphalt is in the glass state; then the asphalt becomes hard solid, showing brittleness; when the temperature is higher, the asphalt is in the viscous flow state, and the asphalt becomes viscous liquid, losing strength; in the middle of the glass state and 


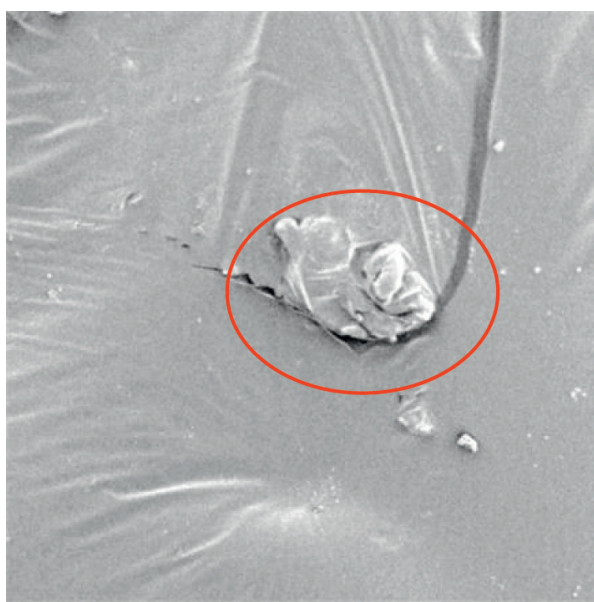

(a)

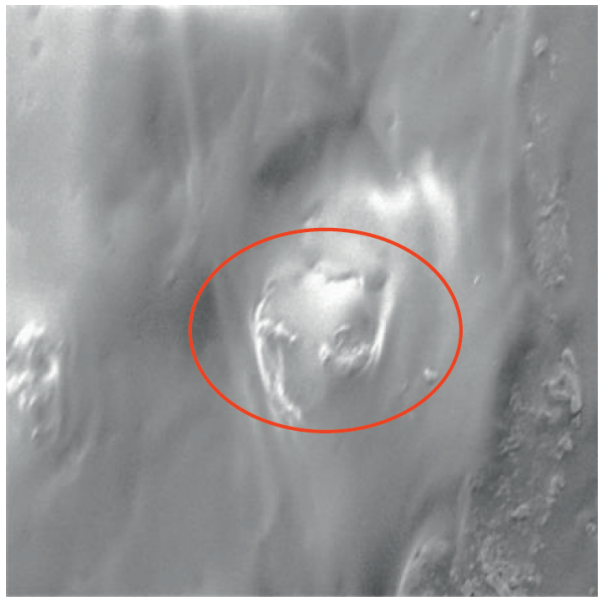

(c)

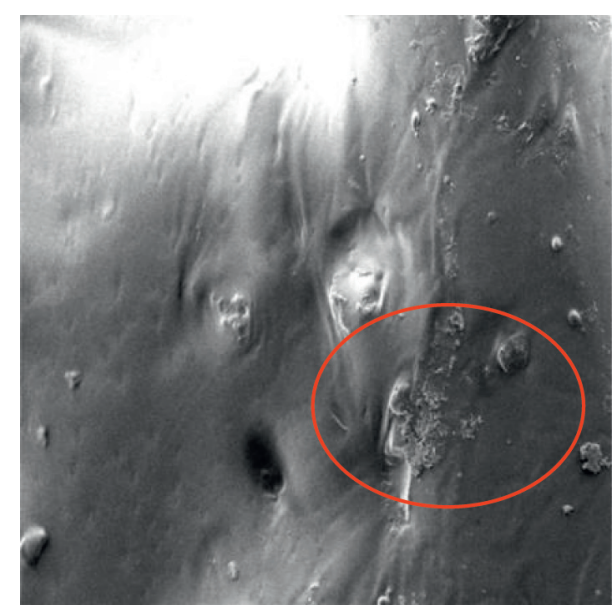

(b)

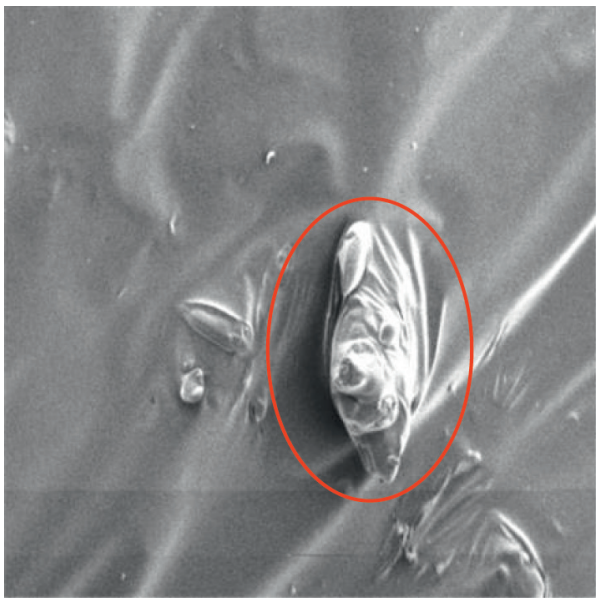

(d)

FIGURE 6: Mirror image of ordinary rubber powder-modified asphalt and activated rubber powder-modified asphalt: (a) ordinary rubber powder-modified asphalt $(\times 200)$, (b) activated rubber powder-modified asphalt $(\times 200)$, (c) ordinary rubber powder-modified asphalt $(\times 500)$, and $(d)$ activated rubber powder-modified asphalt $(\times 500)$.

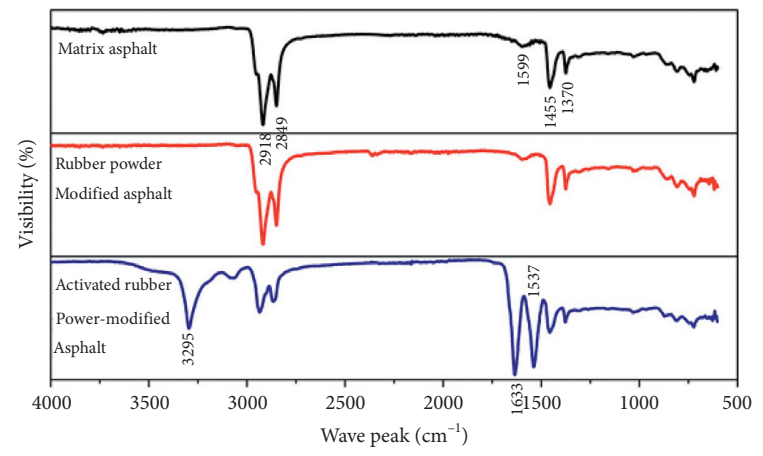

Figure 7: Infrared spectrum test results.

viscous flow state, there is viscoelastic state, and the asphalt is between viscosity and elasticity. There are two temperatures at the boundary of the three states: glass transition temperature and softening temperature. The lower the glass transition temperature of asphalt, the better the low-temperature performance. On the contrary, the higher the softening temperature of asphalt, the better the high- temperature performance. Asphalt and modified asphalt belong to multiphase mixtures. When the above three states change, they will absorb external heat and show an endothermic peak in DSC curve. The magnitude of endothermic peak energy indicates the difficulty of asphalt changing in this state [37]. The larger the endothermic peak energy is, the higher the aggregate transformation number is in the corresponding transformation temperature range and the worse the thermal stability is. The smaller the endothermic peak energy is, the better the thermal stability of the material is.

In the test process, the DSC temperature-heat flow curves of neat asphalt binder, ordinary rubber powdermodified asphalt, and activated rubber powder-modified asphalt were measured. The inflection point of the curve was glass transition temperature and softening temperature. Then the starting and ending points of the endothermic peak were connected as the baseline of the endothermic peak, and the area of the endothermic peak was calculated. The endothermic peak energy is the area of the endothermic peak per unit sample mass [38]. The results are shown in Figures $8 \sim 10$. O is the initial temperature of the endothermic 


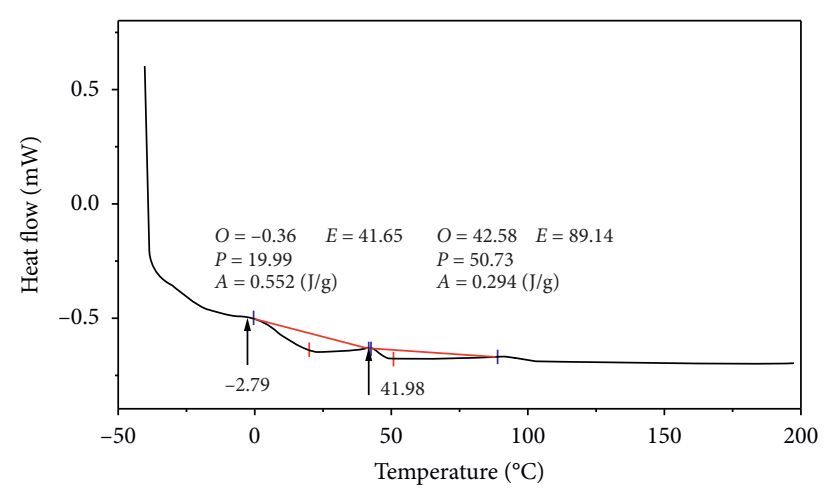

FIgURE 8: DSC results of neat asphalt binder.

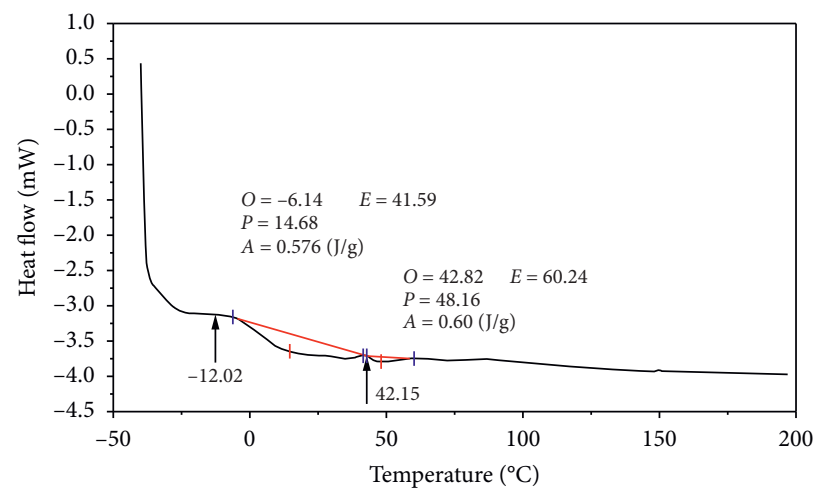

FIGURE 9: DSC results of asphalt modified with ordinary rubber powder.

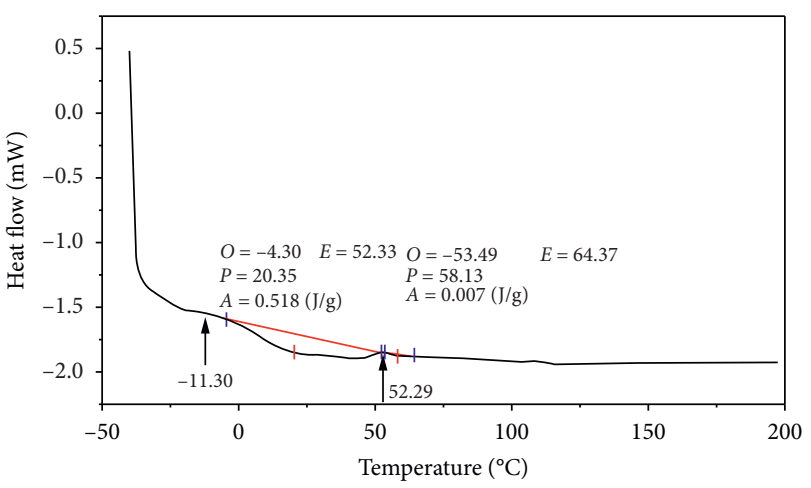

FIGURE 10: DSC results of activated rubber powder-modified asphalt.

peak, $E$ is the end temperature of the endothermic peak, $\mathrm{P}$ is the peak temperature, and $\mathrm{A}$ is the energy of the endothermic peak. The results are listed in Table 5 . In the test, the sample of neat asphalt binder is $3.2 \mathrm{mg}$, the sample of ordinary rubber powder-modified asphalt is $12.3 \mathrm{mg}$, and the sample of activated rubber powder-modified asphalt is $10 \mathrm{mg}$.

As shown in Table 5, the glass transition temperature of activated rubber powder-modified asphalt is lower than that of neat asphalt binder, but slightly higher than that of ordinary rubber powder-modified asphalt. It shows that the activation of rubber powder affects the low-temperature performance of modified asphalt but has little effect. The softening temperature of modified asphalt with activated rubber powder is higher than that of neat asphalt binder and modified asphalt with ordinary rubber powder at $10 \mathrm{C}$, which indicates that activation of rubber powder can improve the high-temperature performance of asphalt. This is mainly because the activation of rubber powder improves the swelling degree of rubber powder in asphalt, makes the cross-linking between rubber powder and asphalt closer, and improves the high-temperature performance of modified asphalt. However, the poor elasticity of polyamide inhibits the elasticity of rubber powder, resulting in the weakening of the overall flexibility of modified asphalt and a slight decrease in the low-temperature performance of modified asphalt.

Table 5 shows that the heat absorption peak energy of neat asphalt binder is high and its thermal stability is poor. The energy of number 1 endothermic peak of ordinary rubber powder-modified asphalt is higher than that of neat asphalt binder, while that of number 2 endothermic peak decreases greatly, which indicates that the thermal stability of asphalt properties becomes worse with the addition of rubber powder, but the stability of modified asphalt is improved at higher temperature. The heat absorption peak energy of modified asphalt with activated rubber powder is much lower than that of neat asphalt binder and modified asphalt with activated rubber powder, which indicates that the properties of modified asphalt with activated rubber 
TABLE 5: DSC test results table.

\begin{tabular}{lcccccc}
\hline Asphalt type & Number & $\begin{array}{c}\text { Energy }(\mathrm{J} / \\
\mathrm{g})\end{array}$ & $\begin{array}{c}\text { Temperature } \\
\left({ }^{\circ} \mathrm{C}\right)\end{array}$ & Width $\left({ }^{\circ} \mathrm{C}\right)$ & $\begin{array}{c}\text { Glass transition temperature } \\
\left({ }^{\circ} \mathrm{C}\right)\end{array}$ & $\begin{array}{c}\text { Softening temperature } \\
\left({ }^{\circ} \mathrm{C}\right)\end{array}$ \\
\hline Neat asphalt binder & 1 & 0.562 & 19.99 & $-0.36 \sim 41.65$ & -2.79 & 41.98 \\
General modified & 2 & 0.310 & 50.73 & $42.58 \sim 89.14$ & & \\
asphalt & 1 & 0.581 & 14.68 & $-4.30 \sim 52.33$ & -12.02 & 42.15 \\
Treated modified & 2 & 0.062 & 48.16 & $53.49 \sim 63.37$ & & \\
asphalt & 1 & 0.532 & 20.35 & $-6.14 \sim 41.59$ & -11.30 & 52.29 \\
\hline
\end{tabular}

powder become stable. This is because after coating and activation of rubber powder, the compatibility between rubber powder and asphalt increases, the modified asphalt is in a uniform state, and its stability is improved.

\section{Conclusion}

In this paper, rheological properties and modification mechanism of rubber-modified asphalt by adding polyamide 6 were studied. The scanning electron microscopy, differential scanning calorimeter test, Fourier transform infrared spectroscopy (FTIR) test, and rheological test were conducted. Some conclusions could be drawn as follows:

(1) Adding polyamide 6 can promote the fusion of waste rubber and asphalt; the compatibility and stability of rubber powder and asphalt binder can be improved by polyimide 6 . And it is an eco-friendly method to increase the consumption of waste rubber.

(2) The modification mechanism is physical blending of rubber powder, additives, and asphalt, but the polymer coated on the surface of the rubber powder with additives can effectively improve the compatibility of the rubber powder with the asphalt and improve the swelling degree of the rubber powder in the asphalt.

(3) The high- and low-temperature performance and fatigue performance of polyimide 6 rubber asphalt mixture will be the focus of the next step.

\section{Data Availability}

All data generated or analyzed during this study are included in this published article.

\section{Additional Points}

Highlights. This paper innovatively proposes the addition of waste rubber to the base of the rubber runway containing polyamide 6 additive. Polyimide 6 rubber asphalt has excellent compatibility and thermal stability. The fusion of the coated rubber and the asphalt is a physical reaction, and no new substance is produced, which is more conducive to the connection between the rubber track base layer and the surface layer and makes the rubber runway more stable.

\section{Conflicts of Interest}

The authors declare no conflicts of interest.

\section{Acknowledgments}

This study was supported by National Natural Science Foundation of China (51838001 and 51878070).

\section{References}

[1] B. Huang, G. Li, S. -S. Pang, and J. Eggers, "Investigation into waste tire rubber-filled concrete," Journal of Materials in Civil Engineering, vol. 16, no. 3, pp. 187-194, 2004.

[2] J. Zhang, L. Ding, F. Li, and J. Peng, "Recycled aggregates from construction and demolition wastes as alternative filling materials for highway subgrades in China," Journal of Cleaner Production, vol. 255, Article ID 120223, 2020.

[3] E. Aylon, A. Fernandez-Colino, M. Navarro, R. Murillo, T. Garcia, and A. Mastral, "Waste tire pyrolysis: comparison between fixed bed reactor and moving bed reactor," Industrial \& Engineering Chemistry Research, vol. 47, no. 12, pp. 4029-4033, 2008.

[4] G. López, M. Olazar, R. Aguado, and J. Bilbao, "Continuous pyrolysis of waste tyres in a conical spouted bed reactor," Fuel, vol. 89, no. 8, pp. 1946-1952, 2010.

[5] B. Yu, L. Jiao, F. Ni, and J. Yang, "Evaluation of plastic-rubber asphalt: engineering property and environmental concern," Construction And Building Materials, vol. 71, pp. 416-424, 2014.

[6] H.-J. Hong, J. S. Lim, J. Y. Hwang, M. Kim, H. S. Jeong, and M. S. Park, "Carboxymethlyated cellulose nanofibrils (CMCNFs) embedded in polyurethane foam as a modular adsorbent of heavy metal ions," Carbohydrate Polymers, vol. 195, pp. 136-142, 2018.

[7] J. Zhang, F. Gu, and Y. Zhang, "Use of building-related construction and demolition wastes in highway embankment: laboratory and field evaluations," Journal of Cleaner Production, vol. 230, pp. 1051-1060, 2019.

[8] M. Cherif Lahimer, N. Ayed, J. Horriche, and S. Belgaied, "Characterization of plastic packaging additives: food contact, stability and toxicity," Arabian Journal of Chemistry, vol. 10, pp. S1938-S1954, 2017.

[9] X. Ding, L. Chen, T. Ma et al., "Laboratory investigation of the recycled asphalt concrete with stable crumb rubber asphalt binder," Construction and Building Materials, vol. 203, pp. 552-557, 2019.

[10] A. Mohajerani, L. Burnett, J. V. Smith et al., "Recycling waste rubber tyres in construction materials and associated environmental considerations: a review," Resources, Conservation and Recycling, vol. 155, Article ID 104679, 2020.

[11] S. Ramarad, M. Khalid, C. T. Ratnam, A. L. Chuah, and W. Rashmi, "Waste tire rubber in polymer blends: a review on the evolution, properties and future," Progress in Materials Science, vol. 72, pp. 100-140, 2015. 
[12] T. Ma, H. Wang, L. He, Y. Zhao, X. Huang, and J. Chen, "Property characterization of asphalt and mixtures modified by different crumb rubbers," Journal of Materials in Civil Engineering, vol. 29, no. 7, Article ID 04017036, pp. 1-10, 2017.

[13] G. Z. Wang Wei and P. Xu, "One-component moisturecuring polyurethane plastic track surface adhesive," China Adhesive, vol. 13, no. 3, pp. 33-36, 2004.

[14] C. Qian, W. Fan, F. Ren, X. Lv, and B. Xing, "Influence of polyphosphoric acid (PPA) on properties of crumb rubber (CR) modified asphalt," Construction And Building Materials, vol. 227, p. 117094, 2019.

[15] Y. Li, P. Cheng, E. A. A. Siddig, and C. Han, "Investigation on thermal aging stability of crosslinked styrene butadiene rubber modified asphalt binder," Road Materials and Pavement Design, pp. 1-16, 2019.

[16] N. M. Azahar, N. A. Hassan, R. P. Jaya et al., "Properties of cup lump rubber modified asphalt binder," Road Materials and Pavement Design, pp. 1-21, 2019.

[17] F. Xiao, S. Yao, J. Wang, J. Wei, and S. Amirkhanian, "Physical and chemical properties of plasma treated crumb rubbers and high temperature characteristics of their rubberised asphalt binders," Road Materials and Pavement Design, vol. 21, no. 3, pp. 587-606, 2018.

[18] H. Wang, X. Liu, H. Zhang, P. Apostolidis, T. Scarpas, and S. Erkens, "Asphalt-rubber interaction and performance evaluation of rubberised asphalt binders containing nonfoaming warm-mix additives," Road Materials and Pavement Design, pp. 1-22, 2018.

[19] M. Arabani, S. A. Tahami, and G. H. Hamedi, "Performance evaluation of dry process crumb rubber-modified asphalt mixtures with nanomaterial," Road Materials and Pavement Design, vol. 19, no. 5, pp. 1241-1258, 2018.

[20] C. Liu, S. Lv, X. Peng, and J. Zheng, "Normalized characterization method for fatigue behavior of cement-treated aggregates based on the yield criterion," Construction and Building Materials, vol. 228, Article ID 117099, pp. 1-9, 2019.

[21] M. I. Souliman and A. Eifert, "Mechanistic and economical characteristics of asphalt rubber mixtures," Advances in Civil Engineering, vol. 2016, Article ID 8647801, 6 pages, 2016.

[22] H. Liu, Z. Chen, W. Wang, H. Wang, and P. Hao, "Investigation of the rheological modification mechanism of crumb rubber modified asphalt (CRMA) containing TOR additive," Construction And Building Materials, vol. 67, pp. 225-233, 2014.

[23] Z. Xie and J. Shen, "Effect of cross-linking agent on the properties of asphalt rubber," Construction And Building Materials, vol. 67, pp. 234-238, 2014.

[24] E. H. Fini, S. Hosseinnezhad, D. Oldham, Z. McLaughlin, Z. Alavi, and J. Harvey, "Bio-modification of rubberised asphalt binder to enhance its performance," International Journal of Pavement Engineering, vol. 20, no. 10, pp. 12161225, 2017.

[25] H. A. A. Gibreil and C. P. Feng, "Effects of high-density polyethylene and crumb rubber powder as modifiers on properties of hot mix asphalt," Construction And Building Materials, vol. 142, pp. 101-108, 2017.

[26] H. Y. Yan Kezhen and Z. Wang, "Study on scrap rubber/ recycled low density polyethylene composite modified asphalt," Journal of Building Materials, vol. 20, no. 1, pp. 145149, 2017.

[27] D. Ge, K. Yan, Z. You, and H. Xu, "Modification mechanism of asphalt binder with waste tire rubber and recycled polyethylene," Construction And Building Materials, vol. 126, pp. 66-76, 2016.
[28] K. L. N. Ng Puga and R. C. Williams, "Low temperature performance of laboratory produced asphalt rubber (AR) mixes containing polyoctenamer," Construction And Building Materials, vol. 112, pp. 1046-1053, 2016.

[29] R. Yu, X. Liu, M. Zhang, X. Zhu, and C. Fang, "Dynamic stability of ethylene-vinyl acetate copolymer/crumb rubber modified asphalt," Construction And Building Materials, vol. 156, pp. 284-292, 2017.

[30] A. H. Kang, W. H. Zhang, and L. J. Sun, "Preparation method of modified asphalt fluorescence optical microscopy sample." Sichuan Daxue Xuebao (Gongcheng Kexue Ban)/Journal of Sichuan University (Engineering Science Edition), vol. 44, pp. 154-158, 2012.

[31] X. J. Li, S. Han, Y. Li, and B. Li, "Experimental study on index of low-temperature crack resistance of asphalt binder," Wuhan Ligong Daxue Xuebao/Journal of Wuhan University of Technology, vol. 32, pp. 81-84, 2010.

[32] Y. C. Guo, B. Zhao, A. Q. Shen, W. T. Jia, and Q. Zhang, "Experimental study on performance of rubber asphalt based on orthogonal design method," Journal of Highway \& Transportation Research \& Development, 2017.

[33] J. Król, P. Radziszewski, K. Kowalski, M. Sarnowski, and P. Czajkowski, "Laboratory and field investigations of polymer and crumb rubber modified bitumen," Journal of Civil Engineering and Architecture, vol. 8, pp. 1327-1334, 2014.

[34] D. Dong, X. Huang, X. Li, and L. Zhang, "Swelling process of rubber in asphalt and its effect on the structure and properties of rubber and asphalt," Construction and Building Materials, vol. 29, pp. 316-322, 2012.

[35] J. P. Zhang, H. Q. Tan, J. Z. Pei, and Q. Tian, "Evaluating crack resistance of asphalt mixture based on essential fracture energy and fracture toughness," International Journal of Geomechanics, vol. 19, no. 4, pp. 17-21, 2019.

[36] J. Zhang, Z. Fan, H. Wang, W. Sun, J. Pei, and D. Wang, "Prediction of dynamic modulus of asphalt mixture using micromechanical method with radial distribution functions," Materials and Structures, vol. 52, no. 2, pp. 49.51-49.12, 2019.

[37] M. R. M. Wang, H. Fazaeli, S. Aghajani, and F. Moghadas Nejad, "Effect of temperature and air void on mixed mode fracture toughness of modified asphalt mixtures," Construction And Building Materials, vol. 95, pp. 545-555, 2015.

[38] C. C. Liu, S. T. Lv, X. H. Peng, J. L. Zheng, and M. Yu, "Analysis and comparison of different impacts of aging and loading frequency on fatigue characterization of asphalt concrete," Journal of Materials in Civil Engineering, 2020. 